\title{
Seeking a comprehensive approach to tobacco control for Aboriginal and Torres Strait Islander people
}

\author{
Reducing smoking rates is essential to closing the health gap between Indigenous \\ and other Australians
}

\section{the TATS \\ project aims \\ to assess the \\ impact of \\ specific policies \\ on smoking \\ behaviour and}

attitudes

Sandra J Eades

BMed, PhD, FAHMS

Catherine Chamberlain

1 Baker IDI Heart and Diabetes Institute, Sydney, NSW.

2 University of Melbourne, Melbourne, VIC.

sandra.eades@ bakeridi.edu.au

doi: 10.5694/mjal5.00455
$\mathrm{T}$ obacco smoking among Aboriginal and Torres Strait Islander people (hereafter we use the term "Aboriginal" to refer to both Aboriginal and Torres Strait Islander peoples, but do so with respect for the autonomy of the two peoples) is the leading cause of health inequities in this population, and its control is essential to "closing the gap" in health status between Aboriginal and other Australians. ${ }^{1}$ Australia, however, currently lacks a comprehensive framework that guides and monitors the effectiveness of tobacco control efforts among Aboriginal people at the local, state and national levels.

In a recent Australian study, the mortality rate for smokers over 45 years of age was three times higher than for non-smokers, and they died about 10 years earlier; twothirds of deaths among smokers could be attributed to their smoking ${ }^{2}$ - and smoking accounts for $20 \%$ of all Aboriginal mortality. ${ }^{3}$ While smoking rates among Aboriginal people are decreasing, $42 \%$ of those aged 15 years or older reported smoking daily in 2012-2013 more than 2.6 times the rate for other Australians. ${ }^{3}$ Of particular concern is that $39 \%$ of young Aboriginal people aged 12-24 years reported smoking daily, ${ }^{4}$ compared with $11 \%$ of young non-Aboriginal people. ${ }^{5}$ These data provide an insight into the substantial health gains that could be achieved were smoking rates among Aboriginal people reduced to the levels for non-Aboriginal Australians. ${ }^{1}$

\section{"Talking About The Smokes"}

The Talking About The Smokes (TATS) project for Aboriginal people complements recent efforts ${ }^{6-8}$ to tackle the problem of smoking in Aboriginal communities. The TATS project is a national collaborative study involving 34 Aboriginal community-controlled health services (ACCHSs), with over 2500 participants and 645 staff involved in 2012 and 2013. As part of the International Tobacco Control Policy Evaluation Project under the World Health Organization Framework Convention on Tobacco Control (FCTC), the TATS project aims to assess the impact of specific policies on smoking behaviour and attitudes. The TATS project found high levels of local knowledge about the risks of smoking. ${ }^{9}$ Most Aboriginal people who smoke wanted to quit, ${ }^{10}$ and about $70 \%$ had actually tried to quit. Aboriginal people in disadvantaged areas were less likely than others to want to quit, ${ }^{11}$ and many disadvantaged smokers who tried relapsed after a short time. ${ }^{12}$

The TATS project has highlighted the role of stress as a key driver of smoking behaviour among Aboriginal people. ${ }^{10}$

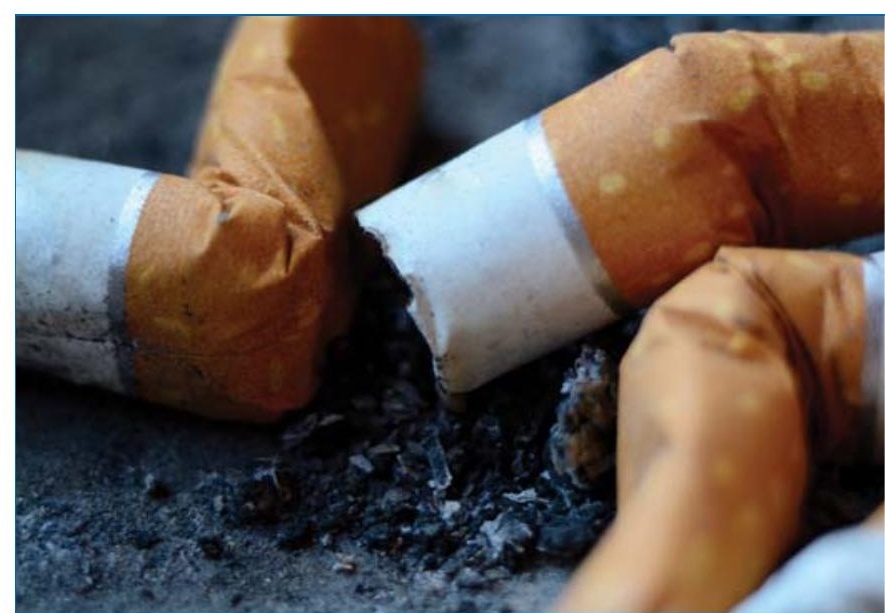

It led researchers to suggest that anti-tobacco messages be reframed to emphasise protecting others from passive smoke exposure, and that sustained targeted anti-tobacco advertising be ensured to reduce the social acceptability of smoking. ${ }^{13}$ The study has called attention to the importance of the role played by local community leaders as opinion leaders, ${ }^{14}$ the commitment of ACCHSs to reducing smoking, ${ }^{15}$ the role of health professional advice, ${ }^{11}$ and the need to improve access to nicotine replacement therapies. ${ }^{16}$ In particular, the TATS project emphasises the importance of broad comprehensive approaches to reducing exposure to passive smoke ${ }^{17}$ and to fighting causes of stress, such as poverty and racism. ${ }^{12}$

The TATS project provides important evidence about smoking behaviour and attitudes, and highlights the need for a broad approach to ensure the development of shared and consistent local, statewide and national strategies for reducing the high rates of smoking among Aboriginal people. ${ }^{12}$ The FCTC, endorsed by the National Preventative Health Taskforce, ${ }^{18}$ accentuates upstream factors, such as regulating the exposure, costs and advertising of tobacco, as well as raising awareness and promoting effective quit programs.

\section{Strategies for tobacco control}

The United States Centers for Disease Control (CDC) has provided additional elements that could be adapted to establish a comprehensive framework for Aboriginal people in its Best practices for comprehensive tobacco control programs. ${ }^{19}$ The CDC guidelines focus on preventing 
smoking initiation in youths and young adults, promoting quitting, eliminating exposure to second-hand smoke and addressing tobacco-related disparities between different population groups. These aims are to be achieved through five overarching strategies:

- State and community interventions that encourage and support tobacco-free norms, such as restrictions on marketing, smoking and sales, as well as reducing exposure to second-hand smoke by expanding smokefree public spaces and workplaces.

- Mass-reach health communication interventions that are sustained, targeted and culturally appropriate, and which reduce the number of young people who start smoking. The TATS project suggests these programs could involve community leaders, like programs developed in the Tackling Indigenous Smoking project.

- Cessation interventions that provide culturally appropriate psychological support and take into account the critical role of stress, and which ensure access to effective pharmacological treatments and continuing support to prevent relapse.
- Ongoing surveillance and evaluation, which is vital to ensuring programs are effective and modified as needed.

- Considerable funding for infrastructure administration and management to sustain current successes and to implement further effective interventions. Current financial constraints create challenges for sustaining comprehensive tobacco control programs, with important programs having already lost funding.

A comprehensive framework to guide tobacco control could be used to pinpoint gaps in current and past strategies, as well as to identify areas for future research, policy and program development. This could include 3- to 5-year smoking strategies developed collaboratively with Indigenous leaders, ACCHSs and services at local, state ${ }^{3}$ and national levels, where efforts will be required over decades to reduce the pernicious impacts of smoking on Aboriginal health.

\section{Competing interests: No relevant disclosures.}

Provenance: Commissioned; not externally peer reviewed.

References are available online at www.mja.com.au. 
1 Vos T, Barker B, Stanley L, Lopez A. The burden of disease and injury in Aboriginal and Torres Strait Islander peoples 2003. Brisbane: University of Queensland, 2007. https://www. lowitja.org.au/sites/default/files/docs/Indigenous-BoDPolicy-Brief.pdf (accessed may 2015).

2 Banks E, Joshy G, Weber MF, et al. Tobacco smoking and allcause mortality in a large Australian cohort study: findings from a mature epidemic with current low smoking prevalence. BMC Med 2015; 13: 38

3 Australian Bureau of Statistics. Australian Aboriginal and Torres Strait Islander Health Survey: first results, Australia, 2012-13. Canberra: ABS, 2013. (ABS Cat. No. 4727.0.55.001.) http://www.abs.gov.au/ausstats/abs@.nsf/mf/4727.0.55.001 (accessed May 2015).

4 Australian Institute of Health and Welfare. The health and welfare of Australia's Aboriginal and Torres Strait Islander people: an overview 2011. Canberra: AlHW, 2011. (AlHW Cat. No. IHW 42.) http://www.aihw.gov.au/WorkArea/DownloadAsset. aspx?id=10737418955 (accessed May 2015).

5 Australian Institute of Health and Welfare. Young Australians: their health and wellbeing 2011. Canberra: AlHW, 2011. (AlHW Cat. No. PHE 140.) http://www.aihw.gov.au/WorkArea/ DownloadAsset.aspx?id=10737419259 (accessed May 2015).

6 New South Wales Ministry of Health. NSW Tobacco Strategy 2012-2017. Sydney: NSW Ministry of Health, 2012. http://www. health.nsw.gov.au/tobacco/Publications/nsw-tobaccostrategy-2012.pdf (accessed May 2015).

7 Eades SJ, Sanson-Fisher RW, Wenitong M, et al. An intensive smoking intervention for pregnant Aboriginal and Torres Strait Islander women: a randomised controlled trial. Med J Aust 2012; 197: 42-46.

8 Marley JV, Atkinson D, Kitaura T, et al. The Be Our Ally Beat Smoking (BOABS) study, a randomised controlled trial of an intensive smoking intervention in a remote Aboriginal primary health care setting. BMC Public Health 2014; 14: 32.

9 Nicholson AK, Borland R, Couzos S, et al. Smoking-related knowledge and health risk beliefs in a national sample of Aboriginal and Torres Strait Islander people. Med J Aust 2015; 202 (10 Suppl): S45-S50.

10 Nicholson AK, Borland R, Bennet PT, et al. Personal attitudes towards smoking in a national sample of Aboriginal and Torres Strait Islander smokers and recent quitters. Med J Aust 2015; 202 (10 Suppl): S51-S56.
11 Nicholson AK, Borland R, Davey ME, et al. Predictors of wanting to quit in a national sample of Aboriginal and Torres Strait Islander smokers. Med J Aust 2015; 202 (10 Suppl): S26-S32.

12 Nicholson AK, Borland R, Davey ME, et al. Past quit attempts in a national sample of Aboriginal and Torres Strait Islander smokers. Med J Aust 2015; 202 (10 Suppl): S20-S25.

13 Nicholson AK, Borland R, Sarin J, et al. Recall of anti-tobacco advertising and information, warning labels and news stories in a national sample of Aboriginal and Torres Strait Islander smokers. Med J Aust 2015; 202 (10 Suppl): S67-S72.

14 Nicholson AK, Borland R, Van der Sterren AE, et al. Social acceptability and desirability of smoking in a national sample of Aboriginal and Torres Strait Islander peoples. Med J Aust 2015; 202 (10 Suppl): S57-S62.

15 Davey ME, Foster R, Van der Sterren AE, et al. Tobacco control policy and activities in Aboriginal community-controlled health services. Med J Aust 2015; 202 (10 Suppl): S63-S66.

16 Thomas DP, Briggs V, Couzos S, et al. Use of nicotine replacement therapy and other stop-smoking medicines by a national sample of Aboriginal and Torres Strait Islander smokers and ex-smokers. Med J Aust 2015; 202 (10 Suppl): S78-S84.

17 Thomas DP, Panaretto KS, Stevens M, et al. Smoke-free homes and workplaces of a national sample of Aboriginal and Torres Strait Islander people. Med J Aust 2015; 202 (10 Suppl): S33-S38.

18 Taking preventative action. A response to Australia: the healthiest country by 2020. The report of the National Preventative Health Taskforce. Canberra: Commonwealth of Australia, 2010. http://www.preventativehealth.org.au/ internet/preventativehealth/publishing.nsf/Content/6B7B176 59424FBE5CA25772000095458/\$File/tpa.pdf (accessed May 2015).

19 US Centers for Disease Control and Prevention. Best practices for comprehensive tobacco control programs - 2014. Atlanta: US Department of Health and Human Services, Centers for Disease Control and Prevention, National Center for Chronic Disease Prevention and Health Promotion, Office on Smoking and Health, 2014. http://www.cdc.gov/ tobacco/stateandcommunity/best_practices/pdfs/2014/ comprehensive.pdf (accessed May 2015). 